\title{
A visita domiciliar como estratégia de cuidado em saúde: reflexões a partir dos Núcleos Ampliados de Saúde da Família e Atenção Básica
}

\author{
Túlio Romério Lopes Quirino \\ Doutor em Psicologia (UFPE). Mestrando em Saúde Coletiva (ISC/UFBA). \\ Chefe da Divisão de Educação na Saúde, Secretaria de Saúde do Recife, PE. \\ $\bowtie$ tulio.quirino@recife.pe.gov.br \\ Adriana Lobo Jucá \\ Mestra em Saúde Pública (Fiocruz/PE). Doutoranda em Saúde da Criança e do Adolescente (UFPE). \\ Terapeuta Ocupacional do NASF-AB, Secretaria de Saúde do Recife, PE. \\ 凹 adrianajuca@gmail.com \\ Luana Padilha da Rocha \\ Mestra em Enfermagem e Educação em Saúde (UFPE). \\ Fisioterapeuta do NASF-AB, Secretaria de Saúde do Recife, PE. \\ $\bowtie \underline{\text { luanapadilha1895@gmail.com }}$ \\ Maria Soraida Silva Cruz \\ Mestra em Saúde da Criança e do Adolescente (UFPE). \\ Terapeuta Ocupacional do NASF-AB, Secretaria de Saúde do Recife, PE. \\ $\square$ soraida_sol@hotmail.com \\ Sémares Genuino Vieira \\ Mestra em Saúde Pública (Fiocruz/PE). \\ Terapeuta Ocupacional do NASF-AB, Secretaria de Saúde do Recife, PE. \\ $\triangle$ semares.v@gmail.com
}

Recebido em 9 de junho de 2020

Aceito em 2 de julho de 2020

\section{Resumo:}

O artigo discute as visitas domiciliares como estratégia de cuidado em saúde no âmbito da Atenção Básica à Saúde, no Brasil, tomando como base a organização de práticas de saúde pelas equipes dos Núcleos Ampliados de Saúde da Família e Atenção Básica (NASF-AB). Partindo da sistematização de experiências coletivas e da problematização do fazer cotidiano, em um espaço de Educação Permanente em Saúde desenvolvido com inspiração nas técnicas do Grupo Operativo, as reflexões empreendidas derivam de oficina realizada junto a profissionais do NASF-AB, da cidade do Recife, Pernambuco, assim como da experiência acumulada por seus autores no desenvolvimento de visitas domiciliares a usuários e famílias sob seus cuidados. Da experiência narrada, revelam-se como resultados apontamentos práticos traduzidos em questões a serem consideradas pelas equipes de saúde nos processos de planejamento, operacionalização e avaliação das visitas domiciliares, tomando sua potência produtiva em concretizar atos de saúde centrados no cuidado e na melhoria da situação de saúde da população assistida. 0 artigo conclui que ao se pautarem nas relações estabelecidas e nas diversas trocas de saberes que delas emergem, as visitas configuram-se como potentes estratégias técnico-assistenciais e pedagógicas para o processo de cuidado em saúde, desvelando efeitos positivos no acompanhamento de usuários e famílias.

Palavras-chave: Visita Domiciliar, Atenção Primária à Saúde, Atenção à Saúde, Saúde da Família, NASF. 


\title{
Home visits as a health care strategy: reflections from the Extended Family Health and Primary Care Support Center
}

\begin{abstract}
:
The article discusses home visits as a health care strategy within the scope of Primary Health Care in Brazil, based on the organization of health practices by the teams of the Extended Family Health and Primary Care Support Centers (NASF-AB). Based on the systematization of collective experiences and the problematization of daily practice, in a space of Permanent Health Education developed with inspiration from the techniques of the Operative Group, the reflections undertaken derive from a workshop held with professionals from NASF-AB, in the city of Recife, Pernambuco, as well as the experience accumulated by its authors in the development of home visits to users and families under their care. From the narrated experience, results are revealed as practical notes translated into issues to be considered by health teams in the planning, operationalization and evaluation processes of home visits, taking their productive power to achieve health acts focused on care and improving the situation health of the assisted population. The article concludes that when guided by the relationships established and the diverse exchanges of knowledge that emerge from them, the visits are configured as powerful technical-assistance and pedagogical strategies for the health care process, revealing positive effects in the monitoring of users and families.
\end{abstract}

Keywords: House Calls, Primary Health Care, Health Care, Family Health, NASF.

\section{Visitas domiciliarias como estrategia de cuidado de la salud: reflexiones de los Nucleos Ampliados de Salud de la Familia y Atención Primaria}

\section{Resumen:}

El artículo analiza las visitas domiciliarias como una estrategia de atención médica dentro del alcance de la Atención Primaria de Salud en Brasil, basada en la organización de prácticas de salud por parte de los equipos de los Nucleos Ampliados de Salud de la Familia y Atencion Primaria (NASF-AB). Con base en la sistematización de experiencias colectivas y la problematización de la práctica diaria, en un espacio de Educación Permanente en Salud desarrollado con inspiración de las técnicas del Grupo Operativo, las reflexiones realizadas se derivan de un taller realizado con profesionales de NASF-AB, en la ciudad de Recife, Pernambuco, así como la experiencia acumulada por sus autores en el desarrollo de visitas domiciliarias a usuarios y familias bajo su cuidado. A partir de la experiencia narrada, los resultados se revelan como notas prácticas traducidas en temas a ser considerados por los equipos de salud en los procesos de planificación, operacionalización y evaluación de las visitas domiciliarias, tomando su poder productivo para lograr actos de salud centrados en la atención y mejorando la situación de salud de la población asistida. El artículo concluye que cuando se guían por las relaciones establecidas y los diversos intercambios de conocimiento que surgen de ellas, las visitas se configuran como poderosas estrategias de asistencia técnica y pedagógicas para el proceso de atención de la salud, revelando efectos positivos en el monitoreo de usuarios y familias.

Palabras clave: Visita domiciliaria, Atención Primaria de Salud, Atención a la Salud, Salud de la Familia, NASF.

\section{INTRODUÇÃo (ou) A constituição do Nasf-AB como dispositivo estratégico de produção do cuidado à saúde no território}

A Atenção Básica à Saúde $(\mathrm{AB})$ pode ser definida como o primeiro nível de contato dos indivíduos, das famílias e da comunidade ao sistema de saúde, com ações individuais e coletivas, voltadas à promoção da saúde, prevenção de agravos, tratamento e reabilitação, 
devendo considerar o sujeito em sua singularidade, complexidade, inteireza e inserção sociocultural (PINTO e GIOVANELLA, 2018; FAUSTO; ALMEIDA; BOSQUAT, 2018; BRASIL, 2011).

O Sistema Único de Saúde brasileiro (SUS) prevê, como estratégia prioritária para reorientação de seu modelo de atenção, a "Saúde da Família", implantada inicialmente como Programa, em 1994, com o objetivo de ser a porta de entrada deste sistema a fim de desenvolver a Atenção Básica de forma integral e resolutiva (GOMES e FRACOLLI, 2018). Atualmente a Estratégia Saúde da Família (ESF) é entendida como organizadora do modelo assistencial, buscando efetivar uma prática orientada na longitudinalidade do cuidado, e tendo a família e seu espaço social como núcleo básico de abordagem no atendimento à saúde (GUIMARÃES et al., 2017; SORATTO et al., 2015; ESCOREL et al., 2007).

A ESF prevê uma equipe mínima, multidisciplinar, composta por um/a médico/a generalista, um/a enfermeiro/a, um/a auxiliar de enfermagem e agentes comunitários de saúde, que assumem a responsabilidade por uma determinada população, em um território definido, onde se desenvolvem suas ações, e tendo como referência física uma unidade básica de saúde. A atuação da equipe de Saúde da Família (eSF) tem como propósito a identificação dos problemas de saúde e das situações de risco existentes da população adstrita, o desenvolvimento de ações educativas e intersetoriais para enfrentar os fatores de risco aos quais a comunidade está exposta, e a efetivação de uma assistência integral às famílias sob sua responsabilidade de forma resolutiva e contínua (GUIMARÃES et al., 2017; BRASIL, 2011; ESCOREL et al., 2007). A Unidade Básica de Saúde (UBS) por sua vez, se insere numa rede de serviços, de forma a garantir atenção integral aos indivíduos e famílias, assegurando a referência e contra referência dos problemas identificados na $\mathrm{AB}$, para os diversos níveis do sistema (BRASIL, 1997).

Com o objetivo de apoiar a inserção da ESF na rede de serviços, o Ministério da Saúde criou os Núcleos de Apoio à Saúde da Família (Nasf), mediante a Portaria GM nº 154, de 24 de janeiro de 2008, republicada em 04 de março de 2008 (BRASIL, 2008), cuja nomeação foi redefinida como Núcleos Ampliados de Saúde da Família e Atenção Básica (Nasf-AB), em 2017, por ação da mais recente revisão da Política Nacional de Atenção Básica (BRASIL, 2017; VENDRUSCOLO et al., 2019). Estes núcleos são compostos por equipes multiprofissionais com atuação integrada aos profissionais das equipes de Saúde da Família, não se constituindo 
como porta de entrada do sistema para os usuários, mas desenvolvendo apoio às eSF (BRASIL, 2009; OLIVEIRA V. et al., 2019).

O trabalho desenvolvido pelo Nasf tem como expoente o fortalecimento de oito diretrizes na atenção à saúde: a interdisciplinaridade, a intersetorialidade, o território, a integralidade, o controle social, a educação permanente em saúde, a promoção da saúde e a humanização (BRASIL, 2008; BROCARDO et al., 2018). Para tal, desde a sua criação foram elencadas como áreas estratégicas para a atuação dessas equipes: atividade física/práticas corporais; práticas integrativas e complementares; reabilitação; alimentação e nutrição; saúde mental; serviço social; saúde da criança, do adolescente e do jovem; saúde da mulher e assistência farmacêutica (BRASIL, 2008; MÂNGIA e LANCMAN, 2008).

O processo de trabalho das equipes Nasf compõe uma série de ferramentas individuais e coletivas, interarticuladas e com diferentes complexidades, destacando-se a construção de Projetos Terapêuticos Singulares (PTS) e Projetos de Saúde no Território (PST), o Apoio Matricial, a Clínica Ampliada e a Pactuação do Apoio, organizando e estruturando atendimentos compartilhados, intervenções específicas dos profissionais do Nasf com usuários e famílias e ações comuns com a eSF nos territórios de sua responsabilidade (SILVA et al, 2019; BRASIL, 2014; BRASIL, 2009).

Quanto ao conceito de Apoio Matricial pode-se entender que se refere ao papel de retaguarda especializada às eSF, possuindo duas dimensões: clínico-assistencial e técnicopedagógica. A dimensão clínico-assistencial configura-se como a ação direta para os usuários de forma coletiva ou individual, e a segunda é direcionada para as eSF, apoiando-as em seu processo de trabalho (SILVA et al., 2019; BRASIL, 2014).

No cotidiano de trabalho das eSF e Nasf, as duas dimensões do apoio matricial influenciam-se mutuamente e estão alicerçadas no pressuposto do conhecimento e da noção de território, compreendido como o lugar onde as pessoas vivem na plenitude de suas características sociais, econômicas, políticas, culturais e afetivas, que se entrelaçam ao processo saúde-doença-cuidado e são fundamentais para o desenvolvimento do trabalho em saúde (OLIVEIRA N. et al., 2019; SANTANA, 2013)

A Atenção Básica, enquanto ordenadora da Rede de Atenção à Saúde, tem no domicílio o seu menor território de atuação, entendido não apenas como uma delimitação espacial onde 
habitam as pessoas, mas como um lugar de experiência existencial, organizado socialmente e caracterizado por relações conflitantes e complementares, com diferentes sentidos e significados, que permitem a tomada de decisão em busca da defesa da vida, transformando o ambiente domiciliar num espaço primordial para promover o cuidado em saúde.

Posto isso, a Visita Domiciliar (VD) apresenta-se como intervenção de excelência, pois tem como objetivo produzir um cuidado integral em saúde, abarcando o que a vida pulsante traz de singular, inusitado e desafiador, melhorando as condições e a qualidade de vida das pessoas pelo exercício da escuta e do apoio e pela implicação, compromisso e potência no agir individual e coletivo, na corresponsabilização do cuidado e no respeito à autonomia, indispensáveis ao fazer em saúde (MAHMUD et al., 2018).

Trazer esta compreensão aqui é importante, para que se possa avançar no propósito deste artigo, qual seja pôr à reflexão o fazer das/nas Visitas Domiciliares (VD), enquanto ferramentas privilegiadas de cuidado desenvolvidas pelas equipes Nasf. Objetivamos, de tal modo, tecer considerações sobre como a estruturação do processo de trabalho de tais equipe possibilita que as VD sejam tomadas como ferramentas privilegiadas para produção da saúde das pessoas, destacando sua positividade no processo de vinculação dos seus atores (eSF, Nasf e usuários), na ordenação e planejamento do cuidado, nas transformações das posturas dos profissionais envolvidos, na valorização dos diferentes saberes implicados, assim como no seu potencial em produzir novos saberes.

\section{METOdologiA (ou) Visitas Domiciliares: Reflexões acerca de um fazer implicado}

As reflexões trazidas neste artigo emergem de um processo situado de trabalho e de constante problematização acerca do fazer profissional, portanto, baseiam-se em "fragmentos" da experiência dos/as seus/suas autores/as quando de sua atuação (como terapeutas ocupacionais, fisioterapeuta e psicólogo) em equipes dos Núcleos Ampliados de Saúde da Família e Atenção Básica (Nasf-AB), da cidade de Recife/PE. Logo, trata-se de uma sistematização da experiência (HOLLIDAY, 2006) que tem como corpus empírico-analítico as vivências do cotidiano e a problematização de suas práticas profissionais em constante 
relação entre si, com outros profissionais e com usuários acompanhados pelas equipes da Atenção Básica à Saúde.

A sistematização da experiência constitui um método para organizar, analisar e comunicar vivências, configurando-se como uma interpretação crítica do que é experienciado. Não se trata apenas de narrar e descrever processos, nem tampouco ordenar informações e dispô-las de maneira sistematizada, mas de proporcionar uma compreensão aprofundada daquilo que é realizado, por meio de reflexões e do compartilhamento de interpretações das pessoas sobre o vivido (HOLLIDAY, 2006).

Desta forma, pretende-se aqui tecer considerações acerca das formas singulares como tais profissionais, em mútua afetação de suas práticas, subjetivam recursos e estratégias de cuidado, no contato diário com as demandas que surgem em seus territórios de atuação. Neste processo, destaca-se a Visita Domiciliar (VD) como importante ferramenta para a organização do trabalho e promoção do cuidado em saúde, e, portanto, dispositivo potente para produzir reflexões acerca desse fazer.

A feitura da visita per se implica em um processo matutante, no qual dimensões variadas do agir em saúde estão imbricadas, englobando desde aspectos organizativos (planejamento, agendamento, avaliação, etc.) a aspectos particulares e subjetivos (queixa, qualificação da demanda, contexto, profissional envolvido, etc.), o que leva ao reconhecimento de que as VD, embora constituam ferramentas de trabalho amplamente difundidas entre as equipes de saúde da $\mathrm{AB}$, apresentam uma complexidade em seu acontecimento, o que por vezes é negligenciado pelos profissionais em vista da naturalização do cotidiano dos serviços, implicando numa perda de sua força terapêutica, de sua potência em produzir saúde e de seu poder em transformar vidas.

Isto posto, no processo de elaboração das provocações trazidas neste trabalho, também merece destaque, espaço singular de discussão acerca da atuação profissional no Nasf, em Recife/PE, do qual participaram seus/suas autores/as, e que teve como temática principal de debate o saber-fazer da/na visita domiciliar. o referido espaço privilegiado de encontro, nomeado "Reunião Distrital Nasf", compõe estratégia sistemática de Educação Permanente em Saúde (EPS) voltada para a problematização do fazer cotidiano e qualificação dos processos de trabalho. Tratam-se de reuniões que apresentam periodicidade bimestral, com duração aproximada de três horas, e que congregam profissionais componentes de todas 
as equipes Nasf vinculadas a um mesmo Distrito Sanitário, conforme ordenamento da rede municipal de saúde.

No tocante ao momento particular destacado, realizou-se um debate teórico-prático e político, alinhado a relatos e depoimentos produzidos pelos participantes deste momento. $\mathrm{Na}$ ocasião, ocorrida em outubro de 2018, estavam presentes 22 profissionais integrantes de cinco diferentes equipes Nasf, que interatuam em territórios contíguos, localizados na zona sul da cidade do Recife. Dentre as categorias profissionais ali representadas, estavam assistentes sociais, psicólogos, terapeutas ocupacionais, fisioterapeutas, nutricionistas, fonoaudiólogas e farmacêuticas, caracterizando a multidisciplinaridade deste espaço, e, portanto, a riqueza de informações que podem ser construídas e compartilhadas entre seus participantes.

O espaço, mediado pela gestão distrital do Nasf, realizou-se como uma oficina produtiva, baseada na técnica do Grupo Operativo (PICHÓN-RIVIERE, 1998) e teve como evento disparador a encenação coletiva de situações em que as equipes operavam visitas domiciliares em seu dia-a-dia. As encenações traziam elementos que detalhavam suas ações, as quais eram avaliadas, pelos próprios profissionais, como bem ou mal sucedidas, possibilitando que o debate sobre tais situações provocasse entre os participantes uma reflexão sobre a própria práxis, levando a uma reelaboração coletiva dos modos de compreender e trabalhar com as visitas, enquanto estratégia de cuidado.

Durante este exercício, foram elaboradas premissas, registradas em cartazes e anotações individuais, que segundo estes/as profissionais, seriam fundamentais ao saberfazer $\mathrm{da} /$ na visita domiciliar. A partir destas premissas, foram estruturados os argumentos apresentados neste artigo, os quais têm como principal objetivo, não apenas a sistematização desta produção, mas a possibilidade de que a tessitura acerca do fazer compartilhado da/na visita promova múltiplas formas de cuidar.

Cabe salientar que não se pretende com tal organização definir formatos, condições ou modelos pré-estabelecidos para a realização das visitas, pelo contrário, a intenção aqui é destacar elementos, fornecer pistas, apontar possibilidades que auxiliem a produção de mais um dentre tantos outros modos de fazer.

\section{RESULTADOS E DISCUSSÃO}




\section{Da Organização do Cuidado à reflexão sobre o fazer profissional}

Planejar, em seu sentido estrito, implica em programar, preparar, organizar previamente um roteiro a ser seguido que conduza a uma determinada finalidade (HOUAISS et al., 2001). O planejamento é, de fato, um aspecto fundamental para qualquer empreendimento, seja ele individual ou coletivo. É o planejamento que possibilita que aquele/a que planeja possa elencar as possibilidades disponíveis para a execução da tarefa pretendida, e, neste processo, antecipar possíveis dificuldades, preparando-se para desfechos inesperados.

Considerando-se isto e tomando a VD como empreendimento corriqueiro do agir em saúde, especialmente no âmbito da $\mathrm{AB}$, é possível identificar a importância da preparação antecipada do ato de visitar. Isto porque é no momento do planejamento que são consideradas as principais informações disponíveis sobre aquele/a a quem se quer visitar, vislumbrando uma melhor adequação da abordagem a ser adotada pelo profissional na condução do seu fazer (SAVASSI, 2016).

Autores como Cunha e Sá (2013), Savassi (2016) e Chimbida e Medeiros (2016) tem sinalizado algumas dificuldades de profissionais da Saúde da Família no planejamento e realização de VD, as quais muitas vezes ficam a cargo dos agentes comunitários de saúde, sem discussão com os demais membros da equipe, além da adoção de condutas burocratizadas, centradas no preenchimento de fichas e ausência de procedimentos padronizados na realização das visitas, bem como por questões relacionais identificadas pelos próprios profissionais.

Destarte tais dificuldades, o planejamento é uma etapa necessária na concretização da atenção domiciliar, sendo neste momento que algumas perguntas-chave podem/devem ser respondidas. Questões estas que possibilitarão o ordenamento da estratégia adotada considerando aspectos fundamentais que não podem ser ignorados (PINHEIRO et al., 2019) .É importante observar, entretanto, que nem sempre todas as informações estarão disponíveis previamente, e, pelo contrário, a própria visita será tomada como mecanismo de obtenção dessas informações (BRASIL, 2014).

Isto posto, a seguir, como resultantes da experiência relatada, são sistematizados e discutidos, sob a forma de interrogações, alguns aspectos pertinentes de serem considerados 
pelos profissionais de saúde quando decidirem lançar mão das visitas domiciliares como estratégia de cuidado. Em nossa compreensão, ponderar tais questões constitui tarefa premente para o sucesso do ato de visitar como prática de saúde.

A) Quem se quer visitar? - É preciso levantar previamente, à medida do possível, as informações disponíveis acerca da pessoa que será escutada, dentre elas, sua história de vida, sua situação socioeconômica, suas crenças, desejos e anseios, suas resistências e pontos de vinculação. Algumas destas informações podem ser obtidas nos documentos habituais de trabalho (fichas, formulários, prontuários), e também a partir de conversas com os profissionais de saúde que já acompanham aquela pessoa, como os agentes comunitários de saúde (ACS), enfermeiros e médicos de família. Outras informações serão obtidas no momento do contato com o usuário, quando da realização da visita.

B) Por que é necessário realizar a visita? - Isto envolve a discussão dos reais motivos que conduziram a equipe de saúde em optar pela realização da visita. Desta forma, implica no levantamento das necessidades, queixas e demandas consideradas, bem como as circunstâncias que fazem com que seja mais indicada a realização de um atendimento no domicílio e não no âmbito do serviço de saúde, ou mesmo de outro equipamento na comunidade.

C) Qual a finalidade da visita? - Embora esta seja talvez a pergunta mais óbvia, nem sempre sua resposta pode ser dada com a mesma simplicidade, uma vez que, fragmentos da experiência sinalizam a existência de inúmeras finalidades na realização de visitas domiciliares; tão inúmeras quanto são as pessoas que são visitadas. Dentre as principais razões, podem ser citadas: o reconhecimento do usuário que precisa de acompanhamento; a realização de procedimentos terapêuticos previamente estabelecidos; a obtenção de informações que conduzirão à definição de um plano de cuidados; ou mesmo, a simples necessidade de "estar-com" o sujeito que precisa de atenção. Tais razões, não se excluem mutuamente, pois em uma mesma visita, estas e outras razões podem estar operando paralelamente, ou como plano de fundo. O que tem que estar claro sempre, vale lembrar, é a razão pela qual foi definida esta estratégia de cuidado, tendo o esclarecimento de que naquele momento, é ela a mais adequada para a realização do acompanhamento do usuário. 
D) Quem realizará a visita? - Esta é outra questão que parece ser fácil de responder, principalmente, quando emerge no contexto em que coexiste uma multiplicidade de categorias profissionais, como é o caso das equipes Nasf. Uma primeira atitude, em geral, observada no momento da discussão de um caso entre os membros de uma equipe multidisciplinar, é a realização de certo "filtro", uma espécie de categorização das queixas que leva à escolha de qual núcleo profissional é o mais adequado para lidar com as mesmas. Assim, num processo quase natural, pessoas com sofrimento mental devem ser visitadas por psicólogos e/ou psiquiatras, pessoas em extrema vulnerabilidade social serão atendidas por assistentes sociais, e, usuários acamados ou com problemas de mobilidade, terão acompanhamento de fisioterapeutas e terapeutas ocupacionais. Tais escolhas, baseadas em queixas, conduzem inúmeras vezes a abordagens equivocadas, uma vez que nem sempre tais queixas consolidam demandas; ou, mesmo, pelo contrário, estas queixas servem exatamente para mascarar as reais necessidades daquele usuário. Assim, a definição de "quem irá realizar a visita" deve resultar da reflexão da equipe acerca da disponibilidade de cada profissional em acolher uma demanda, seja ela qual for. Neste caso, é importante resgatar o sentido fundamental da visita que é o "encontrar o outro", o estar disponível a este encontro, que implica em considerar as próprias resistências e limitações, deixando claro o "dispor-se" (ou não) a cuidar diante daquela situação, naquele momento em que ela está sendo ali discutida. Sendo estas habilidades e atitudes fundamentais ao profissional visitador (SAVASSI, 2016).

E) Quando será realizada a visita? - O agendamento da visita também é um aspecto que merece atenção especial. Considerando que a produção do cuidado em saúde é um processo que se realiza de maneira compartilhada entre profissionais e usuários, os passos necessários à efetivação deste cuidado, por sua vez, também necessitam ser co-conduzidos. Dessa forma, é importante que o momento de realização da visita seja negociado com a pessoa que é a principal interessada - ou seja, aquela que recebe a visita - a qual deve sinalizar o melhor momento (turno, dia, horário etc.) para dispor o seu lar para que "estranhos" venham ao seu encontro (AMARO, 2007). Obviamente, em alguns momentos, como é o caso das intercorrências, esse agendamento prévio não pode ser realizado, mas alguma comunicação ulterior precisa ser estabelecida entre profissionais e usuários acompanhados, sinalizando que ali um processo de cuidado está começando a ser desenvolvido. No caso das equipes Nasf, a comunicação com o usuário ainda ganha outros interlocutores, os profissionais da eSF, em especial os ACS, os quais farão a mediação entre o Nasf e os usuários, tornando o processo de 
negociação ainda mais delicado e complexo, requerendo uma maior atenção aos processos coproduzidos.

F) Que recursos serão mobilizados? - Apesar de ser reconhecida como uma estratégia de baixo-custo, já que seu desenvolvimento demanda fundamentalmente o deslocamento de um profissional a determinado domicílio localizado no território em que este atua, não se pode deixar de considerar que todo ato de saúde mobiliza recursos em sua realização. Assim, é importante levar em conta os aspectos burocráticos, por assim dizer, relacionados à VD, tais como: o tempo a ser despendido e a disponibilidade de agenda dos profissionais envolvidos, a necessidade (ou não) de transporte para que estes acessem o domicílio, materiais e insumos que poderão ser necessários ao atendimento a ser realizado, entre outros (SAVASSI, 2016). Realizar estas pactuações organizativas entre as equipes constitui um momento decisivo para avaliar a viabilidade da estratégia e garantir que esta poderá ser efetivada em tempo oportuno.

G) Quais os possíveis desdobramentos da visita? - Embora possa parecer que esta é uma etapa posterior à realização da VD, é necessário que os profissionais estejam, desde antes, atentos às possibilidades futuras de acompanhamento dos usuários após a ida à sua residência, buscando elementos que facilitem as tomadas de decisão que resultarão da visita. Neste processo estão inclusas as negociações internas junto aos demais profissionais da equipe Nasf, as necessidades de encaminhamento para outros pontos da rede de saúde, a construção de projetos terapêuticos singulares e coletivos, a continuidade do cuidado no domicilio, articulações intersetoriais e comunitárias, dentre outras possibilidades.

Relacionada a estas questões, a avaliação da visita constitui etapa fundamental para a reflexão sobre o processo de cuidado que está sendo construído (PINHEIRO et al., 2019). Mesmo que a avaliação em si seja realizada num momento posterior à execução da visita, no momento do planejamento, algumas pistas podem ser colocadas pelos profissionais que sinalizarão se aquilo que foi pensado previamente será ou não considerado bem sucedido. É como se os profissionais construissem, em paralelo, um "termômetro" que irá funcionar como parâmetro de avaliabilidade da sua atuação no território.

É importante ressaltar que o ato de planejar não pode, no entanto, ser tomado como a primazia do visitar. Mesmo que se definam aspectos que precisam ser considerados (questões 
estruturantes), as visitas domiciliares não devem ser pensadas para seguir rigorosamente a um script, e o planejamento, por sua vez, não deve gerar cristalizações na prática profissional. Assim, um "planejamento flutuante" talvez seja mais indicado, tendo em vista que o profissional necessita estar bem apropriado das informações necessárias à realização da visita (o sujeito, a finalidade etc.), mas também deve considerar as vicissitudes que acompanham o fazer cotidiano na AB. Um fazer que requer a capacidade de lidar com intercorrências, com o inesperado, com aquilo que pode emergir (AMARO, 2007).

É necessário compreender que no dia-a-dia do trabalho na saúde, situações emergenciais aparecem, mesmo nos serviços básicos de atenção, e por isso, o profissional do Nasf deve estar aberto e disponível ao acolhimento das demandas que surgem repentinamente. Logo, este profissional precisa acolher o sujeito que the aparece em sofrimento e efetivar uma prática que possa fornecer uma resposta tal que amenize a criticidade da situação, e que, por sua vez, reconduza aquele usuário à atenção necessária à resolução de sua demanda. Neste caso, é importante que ele possa dispor de um cardápio de múltiplas ofertas, mesmo no imediatismo, que considerem respostas tanto no âmbito comunitário, quanto àquelas que ultrapassam o seu nível de atenção, ou mesmo o seu setor de atuação, podendo demandas ali identificadas serem requalificadas para os setores pertinentes (educação, justiça, assistência social etc.) (SILVA et al., 2019).

\section{Construção de Vínculos e Escuta Qualificada: as visitas domiciliares como caminho de humanização e integralidade}

As informações passadas em consultórios fechados nem sempre são suficientes para entender o indivíduo e seu processo de adoecimento. Assumindo a complexidade que envolve os cuidados com a saúde, a atenção dada ao ambiente e a teia de relações que o indivíduo estabelece quando necessitado de cuidados especiais, tem na VD um importante instrumento para a compreensão dos fenômenos e mudanças que o processo de adoecimento provoca no ambiente domiciliar (MENDES e OLIVEIRA, 2007).

A assistência à saúde no domicílio vai além do simples deslocamento da equipe de saúde à residência do usuário que possui alguma dificuldade de locomoção ou que está restrito ao leito (MAHMUD et al., 2018). A VD pode ser uma importante ferramenta de ligação entre a equipe de saúde e a comunidade possibilitando além da assistência à saúde, o trabalho 
de promoção e prevenção. É importante que, neste espaço, a equipe invista esforços em verificar e compreender o contexto socioeconômico e cultural que envolve o indivíduo/família em seu ambiente mais particular (CANDATEN et al., 2009; SAVASSI, 2016).

Contudo, o simples conhecimento do caso não garante a compreensão dos problemas enfrentados. É necessário um treino no olhar do profissional para compreender o caso de maneira mais aprofundada. Mesmo o reconhecimento das condições de vida, das situações socioeconômicas ou de moradia que interferem no processo saúde-doença não bastam para a solução dos problemas de saúde se não for possível se empenhar na busca de respostas mais potentes para as questões levantadas. A falta de sistematização das visitas, portanto, contribui para desperdício das possibilidades que essa atividade guarda, tornando a VD, na maioria das vezes, mero espelho da consulta (MENDES e OLIVEIRA, 2007).

A VD promove a aproximação da relação entre os profissionais de saúde e os usuários, proporcionando o entendimento do cotidiano destes e a dinâmica familiar, levando a crer que as intervenções que nascem neste contexto têm mais chance de serem efetivadas, tanto pelo compromisso estabelecido entre equipe e a família, como pela relação de confiança gerada dentro do ambiente domiciliar (MAHMUD et al., 2018; CANDATEN et al., 2009).

A riqueza desta ferramenta só pode ser percebida se o profissional puder enxergar não somente um corpo a ser cuidado, mas um ser humano intrinsecamente ligado ao seu ambiente, influenciando e sendo influenciado por ele. É necessário perceber o que pode influenciar na clínica e no cuidado com a pessoa em estado de vulnerabilidade. A vida que ali se encontra sob o cuidado do profissional conta com laços familiares e comunitários que permeiam suas crenças culturais sobre o seu estado atual e que precisam ser consideradas para se propor intervenções compatíveis com a sua realidade (SAVASSI, 2016; MENDES e OLIVEIRA, 2007).

Daí a importância de não enxergar apenas a doença, mas sim o doente. Não o indivíduo em sua enfermidade em geral, mas como ser humano concreto, social e subjetivamente constituído. Deve-se fazer a clínica centrada no sujeito real, em sua existência concreta, também considerando a doença como parte dessa existência. A enfermidade deve ser objeto de intervenção e inclui o sujeito e seu contexto como objetos de estudo e de prática da clínica (CAMPOS, 2013). 
A intervenção domiciliar possibilita o atendimento integral e humanizado, enquanto prática que valoriza o cuidado, como espaço de fortalecimento do trabalho coletivo verdadeiro e facilitador do estabelecimento de vínculo (SAVASSI, 2016; CANDATEN et al., 2009). Vínculo aqui entendido como uma relação dinâmica, com expectativas mútuas, ou seja, do sujeito e do profissional que o atende. Nesta relação podem existir as transferências que serão sempre bilaterais e podem despertar sentimentos negativos ou positivos. Em sua vertente positiva, podem surgir a simpatia e a credibilidade, repercutindo na adesão ao tratamento e às orientações dadas. Do contrário, podem produzir-se a antipatia e a desconfiança, provocando o não cumprimento das orientações e até o abandono do tratamento (CAMPOS, 2013; ALBUQUERQUE et al., 2012).

Nenhum ser humano consegue ser absolutamente racional e frio, e com o profissional de saúde será da mesma forma: ele pode ser afetado pelo modo de ser do individuo. Quando o usuário se sente desvalorizado, dificilmente aderirá ao tratamento sugerido, assim, descobrir qual o tipo de vínculo adequado para cada pessoa é o desafio para qualquer profissional (CAMPOS, 2013).

Uma estratégia que favorece o estabelecimento do vínculo é a escuta qualificada, que possibilita compreender o sofrimento psíquico a partir da pessoa, valoriza suas experiências e atenta para suas necessidades e diferentes aspectos que compõem seu cotidiano. É essencial para que o usuário seja atendido na perspectiva do cuidado como ação integral, além da produção de relações de acolhimento, o respeito à diversidade e à singularidade no encontro entre quem cuida e quem recebe o cuidado (MAYNART et al., 2014).

\section{Visita Domiciliar: (re)descoberta da realidade e compromisso com o protagonismo para resolução de problemas}

Ao longo do tempo, o ideário científico, fundamentado no modelo biomédico reducionista e na especialização corporativista, contribuiu para a produção da saúde afastada da afetividade e do encontro com a subjetividade, aproximando-se de uma prática que privilegia a medicalização e de uma concepção de saúde ditada por padrões e comportamentos considerados ideais (COSTA et al., 2012). No contexto de seu surgimento, as VD não fugiram deste alinhamento, configurando-se inicialmente como estratégias de intervenção por agentes sanitários centradas no controle e detecção de doenças, e, apenas 
posteriormente, atuando na sua prevenção e minimização das dores dos enfermos (SAVASSI, 2016).

Ao mencionar isto, não se pretende aqui criminalizar o caráter assistencial da VD visto que sua prática é institucionalizada e é a partir dela que os profissionais de saúde pautam o direcionamento de suas estratégias de cuidado - mas (re)descobrir diferentes possibilidades e potencialidades de tal ferramenta, para além dos fins histórica e culturalmente a ela atribuídos (MANO, 2009).

Pensar os diferentes modos de fazer a VD implica em entendê-la como fenômeno complexo, que agrega ao acompanhamento do indivíduo no cuidado da sua saúde a implementação do principio da integralidade e a prática educativa, considerando a realidade e o contexto de vida das pessoas, valorizando o vínculo e o conhecimento popular e fortalecendo o trabalho coletivo para a promoção da saúde (CANDATEN et al., 2009; ROMANHOLI e CYRINO, 2012).

Para tanto, não basta apenas o desejo de realizar VD de maneira plural, comprometidas com as dimensões orgânicas, subjetivas e sociais dos usuários. Faz-se necessário aos profissionais superarem os desafios impostos pela aproximação que o domicilio oferece com a dinâmica, o espaço vivo das famílias, em todos os seus aspectos culturais, sociais, religiosos e afetivos que influenciam o modo como elas lidam com as questões relativas à saúde (BOURGET e CRUZ, 2010).

Posto isso, o papel da VD é permitir aos profissionais desenvolverem o exercício do diálogo junto aos usuários, pela criação de um espaço de cumplicidade e intersubjetividade, onde acontecem falas, escutas e interpretações que permitem a apreensão da realidade em seus elementos mais difíceis, intrigantes e conflitantes, o que direciona as práticas em saúde e gera corresponsabilização para enfrentamento dos problemas encontrados (ROMANHOLI e CYRINO, 2012). A partir do diálogo e da troca de saberes, as soluções vão sendo delineadas pelo desenvolvimento de uma ação que extrapola o biologicismo, o autoritarismo profissional, o desprezo pelas iniciativas e conhecimentos dos sujeitos e suas famílias e a imposição de técnicas restritas para problemas sociais globais (VASCONCELOS, 2011).

A experiência de estar no lugar do outro que a VD proporciona permite a obtenção de informações e conhecimentos valiosos no que concerne aos modos como os indivíduos vivem 
e convivem consigo mesmos, com os outros e com o mundo a sua volta, o que abre possibilidades para que profissional e usuário juntos identifiquem as necessidades de saúde, suas causas e modos de enfrentamento, valorizando a prática em si como possível campo de reflexões e de produção de novos saberes, num exercício contínuo de autonomia que revela o caráter emancipatório das VD (CANDATEN et al., 2009; MANO, 2009)

Uma vez compreendida e realizada como prática emancipatória, o trabalhador em saúde tem na VD um instrumento provocador do protagonismo dos sujeitos, por estimular a reflexão sobre a origem dos problemas de saúde e seus determinantes, mediante a contextualização de vida das pessoas, instrumentalizando-as a reconhecerem seus direitos e lutarem por eles, resgatando a condição humana enquanto condição social (CAMPOS et al., 2014).

A VD enquanto ato de escuta, atenção e valorização de subjetividades, experiências prévias, conhecimento adquirido ao longo do tempo e potencial criador dos usuários pode contribuir para a transformação da realidade e mudança do estado de espírito e das atitudes das pessoas diante da vida. Tal resultado não é fruto da execução de procedimentos técnicos ou da vontade de ensinar formas corretas de se viver, mas da criação de uma dinâmica própria e singular dentro do ambiente domiciliar, alicerçada na relação de confiança e no compromisso com o respeito à autonomia firmado entre profissionais e famílias. $O$ que potencializa a compreensão do cuidado para além da dimensão assistencialista e da prática controladora da vida e dos comportamentos em saúde, dando ênfase à VD como mola propulsora do reconhecimento dos usuários como protagonistas em saúde e do seu lugar no processo de transformação social (CANDATEN et al., 2009; VASCONCELOS, 2015; VASCONCELOS, 2011).

\section{CONSIDERAÇõES FINAIS (ou) As Visitas Domiciliares como pedagogia de um fazer em constante transformação}

A VD é, em sua essência, uma ferramenta de trabalho primordial ao cuidado em saúde, particularmente no lugar da $\mathrm{AB}$. A compreensão do domicílio enquanto espaço de (re)união 
de características peculiares e inerentes às pessoas, como seus hábitos, crenças e valores próprios, revela nesse ambiente um grande potencial criativo para a reinvenção das práticas em saúde comprometidas com as necessidades e inventividades do ser humano na superação de problemas que permeiam sua vida.

A partir do reconhecimento dos lares e das relações familiares aí estabelecidas e do entendimento do individuo como ser protagonista do cuidado em saúde, o processo de trabalho dos profissionais que compõem eSF e Nasf precisa ser repensado na perspectiva da efetivação da integralidade da atenção, estimulando a reflexão quanto ao desenvolvimento de práticas compromissadas com o acolhimento, a humanização, a equidade e a participação popular.

A reorientação do modo de fazer saúde na perspectiva do território e do que o domicilio oferece, estando esse incluído na rede de atenção, lança desafios constantes aos profissionais, os quais precisam cotidianamente recriar alternativas que incorporem ao seu processo de trabalho o estabelecimento do vínculo e de uma relação de confiança, a inclusão de sentimentos e questões particulares de quem está sendo cuidado, as riquezas do saber popular e a superação de barreiras impostas pelo racionalismo científico, o que requer uma capacidade de reorganização e readaptação dos profissionais.

Partindo dessa premissa, o enfrentamento das necessidades de saúde de um indivíduo e sua família em toda a complexidade do seu lar requer a mobilização de diferentes saberes e fazeres, compartilhados entre trabalhadores de diferentes categorias profissionais, usuário, família e até mesmo a própria comunidade. Desta forma, é interessante que os profissionais exercitem com frequência uma reflexão crítica sobre suas práticas durante as VD, explorando também suas fragilidades na perspectiva pessoal e de formação, buscando formas de superálas e elaborando novas maneiras de cuidar.

Reconhecendo-se em um processo contínuo de aprendizagem, o profissional das equipes Nasf pode estabelecer uma prática colaborativa interprofissional e interdisciplinar junto às eSF para a construção do modelo integral de cuidado, tendo a visita domiciliar como um dos meios para alcançar este objetivo, sendo ela, portanto, um instrumento potente de EPS. 
A relação estabelecida no ambiente domiciliar entre profissionais de diferentes formações, saberes e visões, e usuários em uma mesma ação, favorece a compreensão integral do processo de saúde-doença, facilitando a troca de conhecimentos e de práticas em ato, gerando novas experiências para os profissionais envolvidos. Sendo assim, ao se pautarem nas relações estabelecidas e nas diversas trocas de saberes que emergem a partir delas, as VD configuram-se como potente estratégia técnico-assistencial e pedagógica a todos os envolvidos no processo de cuidado em saúde.

\section{REFERÊNCIAS}

ALBUQUERQUE, J. F. de; LIMA, M. D. C. A importância da relação entre o profissional de saúde e o paciente. IN: VIEIRA, S.G.; CAVALCANTI, M. S.; SILVA M. G. A; CRUZ, G. A. S. (Org.) O Caminho: Grupo de Humanização. 1 ed. Recife: Editora Universitária da UFPE, 2012. (p. 71-80).

AMARO, S. Visita Domiciliar: Guia para uma abordagem complexa. 2 ed. Porto Alegre: AGE, 2007.

BOURGET, M. M. M.; CRUZ, M. M. A Visita Domiciliária na Estratégia de Saúde da Família: conhecendo as percepções das famílias. Revista Saúde e Sociedade. São Paulo, v.19, n.3, p.605-613, 2010. Disponível em: <https://www.scielo.br/scielo.php?script=sci_arttext\&pid=S0104-12902010000300012>. Acesso em 30 abr. 2020.

BRASIL. Secretaria de Assistência à Saúde. Coordenação de Saúde da Comunidade. Saúde da Família: uma estratégia para a reorientação do modelo assistencial. Brasília (DF): Ministério da Saúde; 1997.

BRASIL. Ministério da Saúde. Portaria no 154 de 24 de janeiro de 2008. Cria os Núcleos de Apoio à Saúde da Família - NASF. Diário Oficial da União. 24 Jan 2008. Disponível em: <https://bvsms.saude.gov.br/bvs/saudelegis/gm/2008/prt0154_24_01_2008.html>. Acesso em 30 abr. 2020.

BRASIL. Secretaria de Atenção à Saúde. Departamento de Atenção Básica. Diretrizes do NASF: núcleo de apoio à saúde da família. Brasília: Ministério da Saúde; 2009.157 p. [Série A. Normas e Manuais Técnicos/Cadernos de Atenção Básica, n. 27].

BRASIL. Ministério da Saúde. Portaria nํ⒉488, de 21 de outubro de 2011. Aprova a Política Nacional de Atenção Básica, estabelecendo a revisão de diretrizes e normas para a organização da Atenção Básica, para a Estratégia Saúde da Família (ESF) e o Programa de Agentes Comunitários de Saúde (Pacs). Diário Oficial da República Federativa do Brasil. Brasília, DF, 22 Out. 2011.

BRASIL. Secretaria de Atenção à Saúde. Departamento de Atenção Básica. Núcleo de Apoio à Saúde da Família: Ferramentas para a gestão e para o trabalho cotidiano. - Brasília: Ministério da Saúde, 2014. 112 p.: il. (Cadernos de Atenção Básica, n. 39).

BRASIL. Ministério da Saúde. Portaria nº 2.436, de 21 de setembro de 2017. Brasília: Ministério da Saúde; 2017.

BROCARDO, D.; ANDRADE, C. L. T.; FAUSTO, M. C. R.; LIMA, S. M. L. Núcleo de Apoio à Saúde da Família (Nasf): panorama nacional a partir de dados do PMAQ. Saúde em Debate [online]. 2018, v. 42, n. spe1, pp. 130-144. Disponível em: <https://doi.org/10.1590/0103-11042018S109>. Acesso em 30 abr. 2020.

CAMPOS, C. M. S.; SILVA, B. R. B; FORLIN, D. C; TRAPÉ, C. A.; LOPES, I. O. Práticas emancipatórias de enfermeiros na Atenção Básica à Saúde: a visita domiciliar como instrumento de reconhecimento de necessidades de saúde. 
Revista da Escola de Enfermagem da USP. São Paulo, v. 48(Esp), p. 119-125, 2014. Disponível em: <https://doi.org/10.1590/S0080-623420140000600017>. Acesso em 30 abr. 2020.

CAMPOS, G. W. S. Saúde Paideia. 4. ed. São Paulo: Hucitec Editora, 2013. (185p).

CANDATEN, A. E; DALEGRAVE, D.; BENACHIO, K. A.; GERMANI, A. R. M. Visita domiciliar: uma estratégia para promover saúde na família e na comunidade. Revista de Enfermagem. Frederico Westphalen, RS: URI Frederico Westph, v. 4/5, n. 4/5, p. 119-126, 2008 . Disponível em: <http://revistas.fw.uri.br/index.php/revistadeenfermagem/article/view/1140>. Acesso em 30 abr. 2020.

CHIMBIDA, G. N.; MEDEIROS, V. A. A visita domiciliar na Atenção Primária à Saúde na perspectiva dos profissionais de saúde de uma UAPS de Betim. Sinapse Múltipla, 5(2), dez., 73-86, 2016. Disponível em: $<$ http://periodicos.pucminas.br/index.php/sinapsemultipla/article/view/12288>. Acesso em 30 abr. 2020.

COSTA, J. R. B.; ROMANO, V. F.; COSTA, R. R.; VITORINO, R. R. ALVES, L. A.; GOMES, A. P.; SIQUEIRA-BATISTA, R. Formação Médica na Estratégia de Saúde da Família: Percepções Discentes. Revista Brasileira de Educação Médica. Rio de Janeiro, v. 36, n. 3, p. 387-400, 2012. Disponível em: <https://doi.org/10.1590/S010055022012000500014>. Acesso em 30 abr. 2020.

CUNHA, M. S.; SÁ, M. C. A Visita Domiciliar na Estratégia de Saúde da Familia: os desafios de se mover no território. Interface - Comunic., Saude, Educ., v.17, n.44, p.61-73, jan./mar. 2013. Disponível em: <https://doi.org/10.1590/S1414-32832013000100006>. Acesso em 30 abr. 2020.

ESCOREL, S.; GIOVANELLA, L; MENDONÇA, M. H. M.; SENNA, M. C. M. O Programa de Saúde da Família e a construção de um novo modelo para a atenção básica no Brasil. Rev. panam. Salud pública/ Pan Am.J. Public Health; 21(2-3):164-176, feb.-mar. 2007. Disponível em: <https://www.scielosp.org/article/rpsp/2007.v21n23/164-176/pt/>. Acesso em 30 abr. 2020.

FAUSTO, M. C. R.; ALMEIDA, P. F.; BOUSQUAT, A. Organização da Atenção Primária à Saúde no Brasil os desafios para a integração em Redes de Atenção. In: In: MENDONÇA, M. H. M. de; MATTA, G. C.; GONDIM, R.; GIOVANELLA, L. (Org.) Atenção Primária à Saúde no Brasil: conceitos, práticas e pesquisa. Rio de Janeiro: Editora Fiocruz, 2018. (pp. 51-72)

GOMES, M. F. P.; FRACOLLI, L. A. Avaliação da estratégia saúde da família sob a ótica dos profissionais. Revista Brasileira em Promoção da Saúde (online), v. 31, p. 1-13, 2018. Disponível em: $<$ https://periodicos.unifor.br/RBPS/article/view/7108>. Acesso em 30 abr. 2020.

GUIMARÃES, M. S. A.; TAVARES, N. U. L.; NAVES, J. O. S.; SOUSA, M. F. Estratégia saúde da família e uso racional de medicamentos: o trabalho dos agentes comunitários em Palmas (TO). Trabalho, Educação e Saúde, Rio de Janeiro, i. 15, n. 1, p. 183-203, jan.:abr. 2017. Disponível em: <https://doi.org/10.1590/1981-7746-sol00037>. Acesso em: 30 abr. 2020.

HOLLIDAY, O. J. Para sistematizar experiências. 2 ed. revista. Brasília: MMA, 2006, 128p.

HOUAISS, A., VILLAR, M. S., FRANCO, F. M. M. Dicionário Houaiss da Língua. Portuguesa. Rio de Janeiro: Instituto Antônio Houaiss de Lexicografia, 2001.

MAHMUD, I. C.; KOWALSKI, C. V.; LAVAGNINI, B. T.; SCHUTZ, K. L.; STOBAUS, C. D.; TERRA, N. L. A multidisciplinaridade na visita domiciliar a idosos: o olhar da Enfermagem, Medicina e Psicologia. Pajar - Pan American Journal of Aging Research, [s.l.], v. 6, n. 2, p.01-72, 21 dez. 2018. Disponível em: < http://revistaseletronicas.pucrs.br/face/ojs/index.php/pajar/article/view/31630> Acesso: 30 abr. 2020.

MÂNGIA, E. F.; LANCMAN, S. Núcleos de Apoio à Saúde da Família: integralidade e trabalho em equipe multiprofissional. Rev. Ter. Ocup. Univ. São Paulo, v. 19, n. 2, p. i, maio/ago. 2008. Disponível em: <http://www.revistas.usp.br/rto/article/view/14030> Acesso: 30 abr. 2020. 
MANO, M. A. M. Casa de família - uma reflexão poética sobre a visita domiciliar e a produção de conhecimento. Revista de Atenção Primária à Saúde. Juiz de Fora, v.12, n.4, p.459-67, 2009. Disponível em: <https://periodicos.ufjf.br/index.php/aps/article/view/14453> Acesso: 30 abr. 2020.

MAYNART, W. H. C.; ALBUQUERQUE, M. C. S; BREDA, M. Z.; JORGE, J. S. A escuta qualificada e o acolhimento na atenção psicossocial. Acta Paul Enferm, 27(4): 300-3, 2014. Disponível em: <https://doi.org/10.1590/19820194201400051> Acesso: 30 abr. 2020.

MENDES, A. O.; OLIVEIRA, F. A. Visitas Domiciliares pela Equipe de Saúde da Família: reflexões para um olhar ampliado do profissional. Revista Brasileira de Medicina da Família e Comunidade, v. 2, p. $253,2007$. Disponível em: <https://rbmfc.emnuvens.com.br/rbmfc/article/view/64> Acesso: 30 abr. 2020.

OLIVEIRA, N. A. O.; MELO, L. A.; OLIVEIRA, M. A. B.; SANTANA; M. M. Territorialização em Saúde e o Nasf. In: QUIRINO, T. R. L.; MARQUES, F. M. A. B.; OLIVEIRA, V. B.; SILVA, E. S.. (Org.) O Nasf e o trabalho na Atenção Básica à Saúde: apontamentos práticos e experimentações. Rio de Janeiro: Editora Fiocruz, 2019.

OLIVEIRA, V. B.; QUIRINO, T. R. L.; CABRAL, B. E. B.; BEZERRA, A. F. B. Apresentando a potência do Nasf na reorientação do fazer saúde na Atenção Básica. In: QUIRINO, T. R. L.; MARQUES, F. M. A. B.; OLIVEIRA, V. B.; SILVA, E. S. (Org.) O Nasf e o trabalho na Atenção Básica à Saúde: apontamentos práticos e experimentações. Rio de Janeiro: Editora Fiocruz, 2019.

PICHON-RIVIÈRE, E. O processo grupal. São Paulo: Martins Fontes, 1998.

PINHEIRO, J. V.; RIBEIRO, M. T. A. M.; FIUZA, T. M.; MONTENEGRO JUNIOR, R. M. Ferramenta para avaliação e gestão da visita domiciliar na atenção primária à saúde: um relato de experiência. Revista Brasileira de Medicina de Família e Comunidade, v. 14, n. 41, p. 1818, 14 maio 2019. Disponível em: <https://rbmfc.org.br/rbmfc/article/view/1818> Acesso: 30 abr. 2020.

PINTO, L. F.; GIOVANELLA, L. Do Programa à Estratégia Saúde da Família: expansão do acesso e redução das internações por condições sensíveis à atenção básica (ICSAB). Ciênc. saúde coletiva [online]. 2018, vol.23, n.6, pp.1903-1914. ISSN 1413-8123. Disponível em: <https://doi.org/10.1590/1413-81232018236.05592018> Acesso: 30 abr. 2020.

ROMANHOLI, R. M. Z.; CYRINO, E. G. A visita domiciliar na formação de médicos: da concepção ao desafio do fazer. Interface - Comunicação, Saúde, Educação. Botucatu, v.16, n.42, p.693-705, 2012. Disponível em: <https://doi.org/10.1590/S1414-32832012000300009> Acesso: 30 abr. 2020.

SANTANA; M. M. Território Plataforma da Vida e do Trabalho Vivo em Saúde: análise do território trabalhado na ESF do DS V em Recife/PE. Dissertação de Mestrado, Recife: Instituto Aggeu Magalhães, Fundação Oswaldo Cruz, 2013.

SAVASSI, L. C. M. Os atuais desafios da Atenção Domiciliar na Atenção Primária à Saúde: uma análise na perspectiva do Sistema Único de Saúde. Revista Brasileira de Medicina de Família e Comunidade, 11(38), p. 1-12, 2016. Disponível em: <https://www.rbmfc.org.br/rbmfc/article/view/1259> Acesso: 30 abr. 2020.

SILVA, E. S.; JUCÁ, A. L.; AMADO, C. F.; ROCHA, L. P.; VASCONCELOS, T. F.; QUIRINO, T. R. L. Processos de trabalho e ferramentas tecnológicas de atuação do Nasf. In: QUIRINO, T. R. L.; MARQUES, F. M. A. B.; OLIVEIRA, V. B.; SILVA, E. S. (Org.) O Nasf e o trabalho na Atenção Básica à Saúde: apontamentos práticos e experimentações. Rio de Janeiro: Editora Fiocruz, 2019.

SORATTO, J.; PIRES, D. E. P.; DORNELLES, S.; LORENZETTI, J. Estratégia saúde da família: uma inovação tecnológica em saúde. Texto contexto - enferm., Florianópolis, v. 24, n. 2, p. 584-592, Jun, 2015. Disponível em: <https://doi.org/10.1590/0104-07072015001572014> Acesso: 30 abr. 2020.

VASCONCELOS, E. M. Educação Popular e atenção à saúde da família. 6. ed. São Paulo: Hucitec Editora, 2015. (334p). 
VASCONCELOS, E. Educação Popular na Formação Universitária: reflexões com base em uma experiência. São Paulo: HUCITEC, 2011. (419p).

VENDRUSCOLO, C.; FERRAZ, F., TESSER, C. D.; TRINDADE, L. de L. Núcleo Ampliado de Saúde da Família: espaço de interseção entre Atenção Primária e Secundária. Texto contexto - enferm., Florianópolis, v. 28, e20170560, 2019. Disponível em: <https://doi.org/10.1590/1980-265x-tce-2017-0560> Acesso: 30 abr. 2020.

\section{(cc) EY}

Este trabalho está licenciado com uma Licença Creative Commons - Atribuição 4.0 Internacional. 